\title{
Adiponectin stimulates glucose uptake in mouse blastocysts and embryonic carcinoma cells
}

\author{
J Burkušr , A Navarrete Santos², M Schindler², J Babel'ová1, J S Jung², A Špirková1, M Kšiňanová1, \\ V Kovaříková1, B Fischer ${ }^{2}$, J Koppel ${ }^{1}$, D Fabian ${ }^{1}$ and Š Čikoš ${ }^{1}$ \\ ${ }^{1}$ Institute of Animal Physiology, Centre of Biosciences of the Slovak Academy of Sciences, Košice, Slovakia and \\ ${ }^{2}$ Department of Anatomy and Cell Biology, Faculty of Medicine, Martin Luther University Halle Wittenberg, Halle, \\ Saale, Germany \\ Correspondence should be addressed to Š Čikoš; Email: cikos@saske.sk
}

\begin{abstract}
Preimplantation embryos are sensitive to maternal hormones affecting embryonic signal transduction and metabolic functions. We examined whether adiponectin, the most abundantly secreted adipokine, can influence glucose transport in mouse embryonic cells. In mouse blastocysts full-length adiponectin stimulated glucose uptake, while no effect of globular adiponectin was found. Full-length adiponectin stimulated translocation of GLUT8 glucose transporter to the cell membrane; we did not detect significant changes in the intracellular localization of GLUT4 glucose transporter in adiponectin-treated blastocysts. To study adiponectin signaling in detail, we used embryoid bodies formed from mouse embryonic carcinoma cell (ECC) line P19. We confirmed the expression of adiponectin receptors in these cells. Similar to mouse blastocysts, full-length adiponectin, but not globular adiponectin, stimulated glucose uptake in ECC P19 embryoid bodies. Moreover, full-length adiponectin stimulated AMPK and p38 MAPK phosphorylation. These results indicate that besides AMPK, p38 MAPK is a potential target of adiponectin in mouse embryonic cells. AMPK inhibitor did not influence the adiponectin-stimulated p38 MAPK phosphorylation, indicating independent action of these two signaling pathways. In mouse embryos adiponectin acts as a hormonal regulator of glucose uptake, which becomes especially important in phases with reduced levels of circulating insulin. Our results suggest that adiponectin maintains the glucose supply for early embryos under hypoinsulinaemic conditions, for example, in mothers suffering from type $\mathbf{1}$ diabetes mellitus.
\end{abstract}

Reproduction (2020) 159 227-239

\section{Introduction}

The preimplantation embryo requires adequate energy production and distribution. Glucose is the main energy source from the blastocyst stage onwards (Pantaleon \& Kaye 1998), and preimplantation embryos of various mammalian species express several facilitative glucose transporters (SLC2A/GLUT family, for review see Purcell \& Moley 2009). Experiments using rabbits have shown that adiponectin, the most abundantly secreted adipokine, can stimulate glucose uptake in blastocysts, and the increase in glucose transport was connected with translocation of glucose transporter GLUT4 into the cell membrane (Fischer et al. 2010). Interestingly, insulin stimulus neither induced GLUT4 translocation nor increased glucose uptake in rabbit blastocysts (Navarrete Santos et al. 2004a). This is in contrast with the mouse, where insulin has been shown to stimulate blastocyst glucose uptake via IGF1 receptor-mediated translocation of GLUT8 glucose transporter (Pantaleon \& Kaye 1996, Carayannopoulos et al. 2000, Pinto et al. 2002). These results suggest possible interspecies differences in the regulation of blastocyst glucose uptake, which seems to be insulin- and IGF1-dependent in the mouse, and insulin-independent/adiponectin-stimulated in the rabbit. On the other hand, since adiponectin receptors have been detected in blastocysts of several mammalian species (for review see Čikoš 2012), adiponectinregulated glucose transport could exist in blastocysts of other species as well.

Two insulin- or adiponectin-responsive facilitative glucose transporters have been identified in preimplantation embryos. Both GLUT4 (SLC2A4) and GLUT8 (SLC2A8) were found in bovine and rabbit blastocysts (Navarrete Santos et al. 2000, 2004b, Augustin et al 2001). GLUT4 was also detected in rat blastocysts (Korgun et al. 2001) and GLUT8 was identified in mouse and hamster blastocysts (Carayannopoulos et al. 2000, Pinto et al. 2002, Tonack et al. 2009). A controversy exists on the expression of GLUT4 in mouse blastocysts (Tonack et al. 2004 vs Hogan et al. 1991, Aghayan et al. 1992).

The aim of this study was to examine whether adiponectin can stimulate glucose uptake in mouse 
blastocysts, and whether GLUT4 and GLUT8 are involved in a possible adiponectin-regulated glucose transport. Embryoid bodies (EBs) developed from mouse embryonic carcinoma P19 (ECC P19) cells were used as a model for studying adiponectin signaling in embryonic cells. To validate this model, we verified the expression of adiponectin receptors in ECC P19 EBs. Finally, we analysed glucose uptake and activation of the adiponectin signaling pathway in the ECC P19 EBs.

\section{Materials and methods}

\section{Embryo recovery}

Female mice (CD-1 strain, 4 to 7 weeks old, Velaz, Prague, Czech Republic and Charles River, Freiburg, Germany) underwent superovulation treatment with intraperitoneal injection of $4 \mathrm{IU}$ of serum gonadotropin (Folligon, Intervet International $\mathrm{Bv}$. Boxmeer, Holland), followed $47 \mathrm{~h}$ later by administration of $4 \mathrm{IU}$ of human chorionic gonadotropin (hCG, Organon, Oss, Holland). Twelve to fourteen hours after hCG administration, the mice were killed by cervical dislocation, and unfertilized oocytes were isolated by flushing from the oviduct. To obtain preimplantation embryos, females were mated with males of the same strain overnight (mating was confirmed by identification of a vaginal plug) and killed by cervical dislocation (57-, 72-, 86- or $98 \mathrm{~h}$ after hCG administration), and the embryos (4-cell, 8- to16-cell embryos, morulas and blastocysts) were isolated by flushing from the oviduct and/or uterus. Oocytes and embryos were washed in several drops of FHM medium (Lawitts \& Biggers 1993) containing 1\% BSA (Sigma-Aldrich) and pooled according to their morphology. Cumulus cells were removed with $0.1 \%$ hyaluronidase (Sevac, Prague, Czech Republic). All animal experiments were performed in accordance with the principles of the Ethical Committee for Animal Experimentation at the Institute of Animal Physiology, and approved through the State Veterinary and Food Administration of the Slovak Republic (Ro 3155/14-221) and Germany (MLU I11M21) in strict accordance with legislation based on EU Directive 2010/63/ $\mathrm{EU}$ on the protection of animals used for experimental and other scientific purposes. All efforts were made to reduce animal suffering and distress and to minimize the number of animals necessary to produce reliable results.

\section{Mouse embryonic carcinoma P19 cell culture}

Mouse embryonic carcinoma cells (ECC) line P19 (McBurney et al. 1982) were cultured under standard conditions (5\% $\mathrm{CO}_{2}$ and $37^{\circ} \mathrm{C}$ ) on gelatin $(0.1 \%)$-coated tissue culture dishes in DMEM (Invitrogen) supplemented with 15\% heat inactivated fetal calf serum (selected batches of Biochrom KG, Berlin, Germany), L-glutamine (2 mm; Life Technologies, Inc.), $\beta$-mercaptoethanol (final concentration $50 \mathrm{~mm}$; Serva, Heidelberg, Germany), nonessential amino acids (stock solution diluted 1:100; Invitrogen), and streptomycin/ ampicillin $(5000 \mathrm{U} / \mathrm{mL}$ ampicillin, $5000 \mu \mathrm{g} / \mathrm{mL}$ streptomycin; Invitrogen) (Tonack et al. 2007). Drops of differentiation medium $(20 \mu \mathrm{L})$ with 400 cells were placed onto the lids of Petri dishes filled with PBS and cultured for 2 days. Cell aggregates formed in the hanging drops were transferred into non-adhesive bacteriologic- grade Petri dishes $(6 \mathrm{~cm})$ containing $5 \mathrm{~mL}$ culture medium to develop older (4-6 days old) embryoid bodies (EBs; Wobus et al. 1994).

\section{RNA isolation and CDNA synthesis}

To analyse expression of glucose transporter (GLUT4, GLUT8) and adiponectin receptor (AdipoR1, AdipoR2, T-cadherin) transcripts, total RNA was extracted from batches of 80-100 mouse blastocysts, early stage embryos and oocytes, from 15 ECC P19 embryoid bodies, and also from mouse heart and brain (positive controls). TRIzol Reagent (Invitrogen Life Technologies) was used for the extraction according to the manufacturer's instructions. Contaminating DNA in RNA preparations was digested with amplification-grade DNase I (Invitrogen Life Technologies). Three independent experiments were performed, using separate batches of embryos or embryoid bodies for the RNA isolation.

The RNA (from 80 to 100 embryos or $0.5 \mu \mathrm{g}$ RNA from ECC P19 embryoid bodies, heart or brain) was reverse transcribed with Superscript ${ }^{T M}$ III RNase $\mathrm{H}^{-}$Reverse Transcriptase (Invitrogen Life Technologies) using $4 \mu \mathrm{M}$ anchored oligo dT primers and $1.5 \mu \mathrm{M}$ random hexamer primers (Thermo Fisher Scientific ABgene). To check for the presence of genomic DNA contamination in the RNA preparations, reverse transcriptase negative controls (no reverse transcriptase in the reaction) were carried out in parallel, using part of each RNA sample. The cDNA preparations were then cleaned by ethanol precipitation, and the cDNA pellets from blastocysts were diluted in an appropriate amount of $10 \mathrm{mM}$ Tris $(\mathrm{pH}$ 8.3) so that $1 \mu \mathrm{L}$ of the cDNA corresponded to 2.5 embryo equivalents or to 25 ng of ECC P19 total RNA.

\section{PCR and PCR product analysis}

PCR amplifications were carried out in $25 \mu \mathrm{L}$ volumes containing $1 \mu \mathrm{L}$ of cDNA, $0.5 \mu \mathrm{M}$ of each oligonucleotide primer, $50 \mathrm{mM} \mathrm{KCl}, 10 \mathrm{mM}$ Tris- $\mathrm{HCl} \mathrm{pH} 8.3,2 \mathrm{mM} \mathrm{MgCl}$, $0.2 \mathrm{mM}$ dNTPs (dATP, dTTP, dCTP, dGTP) and 0.04 units/ $\mu \mathrm{L}$ Platinum Taq DNA polymerase (Invitrogen Life Technologies). For detection of GLUT4 and GLUT8 transcripts in blastocysts we used primers designed by Tonack et al. (2004), for detection of AdipoR1 and AdipoR2 transcripts in ECC P19 embryoid bodies we used primers designed by Schmidt et al. (2008), and for detection of T-cadherin transcripts in blastocysts and ECC P19 embryoid bodies we used primers designed by Zhou et al. (2002). An initial denaturation step at $95^{\circ} \mathrm{C}$ for 2 min was followed by 35 (ECC P19, heart and brain CDNAs) or 40 (blastocyst cDNAs) cycles at $94^{\circ} \mathrm{C}$ for $30 \mathrm{~s}, 60^{\circ} \mathrm{C}$ (GLUT4, GLUT8, AdipoR1 and AdipoR2) or $64^{\circ} \mathrm{C}$ (T-cadherin) for $30 \mathrm{~s}$ and $72^{\circ} \mathrm{C}$ for $60 \mathrm{~s}$. To check for the presence of cross contamination, the reaction with water instead of cDNA was performed concurrently (blank reaction).PCR products were analysed using electrophoresis on a $2 \%$ agarose gel stained with GelGreen (Biotium, Hayward, USA), and 100-bp DNA ladder (Jena Bioscience, Jena, Germany) was used as a marker to determine the size of PCR products. PCR products were 
sequenced (GATC Biotech AG, Konstanz, Germany), and the obtained sequences were compared (using Clustal $W$ and Blast 2 algorithms) with known mRNA sequences of mouse GLUT4, GLUT8, AdipoR1, AdipoR2 and T-cadherin (GenBank accession numbers NM_009204, NM_019488, NM_028320, NM_197985 and NM_019707 respectively).

\section{Real-time PCR relative quantification of $m R N A$}

To compare relative quantities of AdipoR1 and AdipoR2 transcripts as well as GLUT4 and GLUT8 transcripts in mouse blastocysts and ECC P19 EBs, we amplified these sequences using real-time PCR with SYBRGreen fluorescent dye. Amplification efficiency, threshold fluorescence and Ct values were measured in each amplification, and starting fluorescences were then calculated. The theoretical starting fluorescence is proportional to the amount of PCR template in the sample, and represents the quantity of target nucleic acid sequence expressed in arbitrary fluorescence units (Liu \& Saint 2002, Peirson et al. 2003, Ramakers et al. 2003, Čikoš \& Koppel 2009).

PCR amplifications for the quantitative analysis were performed in the Mx 3000P real-time PCR system (Stratagene, La Jolla, CA, USA). The reactions were carried out in $25 \mu \mathrm{L}$ volumes containing $1 \mu \mathrm{L}$ of cDNA, $1 \times$ PCR Master Mix with SYBR Green (Qiagen), and $0.4 \mu \mathrm{M}$ of each specific forward and reverse primer. For adiponectin receptors (AdipoR1 and AdipoR2) we used primers designed by Schmidt et al. (2008), and for glucose transporters (GLUT4 and GLUT8) and beta actin (ActB) we used primer assays from Qiagen (GLUT4: Slc2a4 assay \#PPM04166F, GLUT8: Slc2a8 assay \#PPM041165A, ActB: ActB assay \#PPM02945B). An initial step at $95^{\circ} \mathrm{C}$ for $10 \mathrm{~min}$ was followed by 40 cycles (or 36 cycles for ActB and 45 cycles for GLUT4) at $95^{\circ} \mathrm{C}$ for $20 \mathrm{~s}$, $64^{\circ} \mathrm{C}$ (AdipoR1), $66^{\circ} \mathrm{C}$ (AdipoR2) or $65^{\circ} \mathrm{C}$ (GLUT4, GLUT8, ActB) for $30 \mathrm{~s}, 72^{\circ} \mathrm{C}$ for $20 \mathrm{~s}$ and $78^{\circ} \mathrm{C}$ (or $83^{\circ} \mathrm{C}$ for $\mathrm{ActB}$ ) for 20 $\mathrm{s}$ (acquiring of fluorescence). Fluorescence was measured after the elongation step. Amplification specificity was checked using melting curve analysis.

Amplification efficiency was measured with the use of a relative standard curve and LinRegPCR software (Ramakers et al. 2003). Theoretical starting fluorescence for each analyzed sequence (AdipoR1, AdipoR2, GLUT4, GLUT8) and for reference gene (ActB) in each sample was calculated using the formula:

$$
\mathrm{R}_{0}=\mathrm{R}_{\mathrm{Ct}} /(\mathrm{E}+1)^{\mathrm{Ct}}
$$

where $R_{0}$ is the starting fluorescence (proportional to the amount of PCR template), $R_{C t}$ is the threshold fluorescence value, $E$ is the amplification efficiency and $\mathrm{Ct}$ is the fractional cycle number necessary for reaching the threshold fluorescence (Čikos \& Koppel 2009). The calculated starting fluorescences were corrected for the PCR product length ( $R_{0 b p}$ values, obtained by dividing the $R_{0}$ value with the PCR product length in bps). Validation of this procedure was done in a preliminary experiment (Supplementary Table 1, see section on supplementary materials given at the end of this article). To normalize target gene quantities, AdipoR1, AdipoR2, GLUT4 and GLUT8 starting fluorescences were divided by ActB starting fluorescences.

\section{Immunostaining}

We used the immunofluorescence technique to localise expression of GLUT4 and GLUT8 proteins in mouse blastocysts, and expression of AdipoR1and AdipoR2 proteins in ECC P19 embryoid bodies. To examine the effect of adiponectin on GLUT4 and GLUT8 intracellular localization we stimulated mouse blastocysts with adiponectin. The blastocysts were isolated as described above and cultured under standard conditions $\left(5 \% \quad \mathrm{CO}_{2}\right.$ and $37^{\circ} \mathrm{C}$; $\mathrm{KSOM}$ culture medium, Specialty Media Group, Phillipsburg, NJ, USA) for 45 min in the presence or absence of adiponectin. The culture drops of adiponectin-stimulated blastocysts were supplemented with full-length adiponectin (mouse Acrp30, recombinant protein, produced in HEK 293 cells, BioVendor) at a final concentration of $10 \mu \mathrm{g} / \mathrm{mL}$. No supplement was added in the culture drops of control blastocysts. Blastocysts were fixed in $4 \%$ paraformaldehyde, then they were washed in PBS/BSA and permeabilized for $1 \mathrm{~h}$ in PBS with $0.5 \%$ Triton X-100 (Sigma-Aldrich). Free aldehyde groups were blocked with $0.1 \mathrm{M}$ glycine (Merck), and washed in PBS/BSA. Non-specific immunoreactions were blocked with $10 \%$ normal goat serum (Santa Cruz Biotechnology) for $2 \mathrm{~h}$ at room temperature. The blastocysts were then incubated with primary antibodies raised against mouse GLUT4 or GLUT8 (purchased from LifeSpan BioSciences, Seattle, WA, USA; for detailed information see Table 1 ) in $10 \%$ goat serum at $4{ }^{\circ} \mathrm{C}$ overnight. Specific secondary antibody coupled with Alexa Fluor 488 (Alexa Fluor 488 goat anti-rabbit IgG, Invitrogen Life Technologies) was used to visualize primary antibodies (30 min at room temperature). Cell nuclei were stained with Hoechst 33342 in PBS/BSA (20 $\mu \mathrm{g} / \mathrm{ml}$; Sigma-Aldrich). Afterwards, the blastocysts were mounted in ProLong Gold antifade reagent (Molecular Probes, Invitrogen) on glass slides, sealed with coverslips and observed using a confocal microscope (Leica TCS SP5, Leica Microsystems). Negative control groups of embryos were incubated without the primary antibody or without the primary and secondary antibody.

ECC P19 embryoid bodies (EBs) were prepared as described above. EBs were fixed, dehydrated for paraffin embedding, sectioned and attached to slides as described previously (Tonack et al. 2006). The slides were incubated in a heating cabinet $\left(60^{\circ} \mathrm{C}\right)$ over night, then dewaxed in xylene and rehydrated through a series of graded alcohols. For AdipoR1 detection, a heat-induced antigen retrieval step in $20 \mathrm{mM}$ at $\mathrm{pH} 9$ was included. After washing in PBST (PBS with $0.1 \%$ Tween), nonspecific antibody binding was blocked with $10 \%$ normal goat serum in PBS for $1 \mathrm{~h}$ at room temperature. The sections were incubated with primary antibodies raised against adiponectin receptor 1 or adiponectin receptor 2 (purchased from LifeSpan BioSciences, Inc. and Alpha Diagnostic International, San Antonio, TX, USA; for detailed information see Table 1) in 10\% goat serum at $4{ }^{\circ} \mathrm{C}$ overnight. Afterwards, the sections were incubated with secondary antibody coupled with Alexa Fluor 
Table 1 Primary antibodies used in the study.

\begin{tabular}{|c|c|c|c|c|}
\hline Antibody name & $\begin{array}{l}\text { Host species and } \\
\text { antibody clonality }\end{array}$ & Application & Dilution used & Source, catalog \# \\
\hline SLC2A4/GLUT4 Antibody (aa480-509) & Rabbit polyclonal & $\mathrm{IHC}$ & $1: 200$ & LifeSpan BioSciences \# LS-C143467 \\
\hline SLC2A8/GLUT8 Antibody (aa461-477) & Rabbit polyclonal & $\mathrm{IHC}$ & $1: 200$ & LifeSpan BioSciences \#LS-C313271 \\
\hline $\begin{array}{l}\text { Adiponectin Receptor } 1 \text { Antibody } \\
\text { (C-Terminus) }\end{array}$ & Rabbit Polyclonal & $\mathrm{IHC}$ & $1: 100$ & LifeSpan BioSciences \# LS-C151518 \\
\hline $\begin{array}{l}\text { Adiponectin Receptor } 2 \text { (ADIPOR2) } \\
\text { Antibody }\end{array}$ & Rabbit polyclonal & $\mathrm{IHC}$ & $1: 100$ & $\begin{array}{l}\text { Alpha Diagnostic International \# } \\
\text { ADIPOR22-A }\end{array}$ \\
\hline AMPK $\alpha$ Antibody & Rabbit polyclonal & Western & 1:1000 & Cell Signaling Technology, \# 2532 \\
\hline Phospho-AMPK $\alpha$ (Thr172) Antibody & Rabbit polyclonal & Western & 1:1000 & Cell Signaling Technology, \# 2531 \\
\hline $\begin{array}{l}\text { Phospho-Acetyl-CoA Carboxylase } \\
\text { (Ser79) Antibody }\end{array}$ & & Rabbit polyclonal & Western & $\begin{array}{l}\text { 1:1000 Cell Signaling Technology, \# } \\
3661\end{array}$ \\
\hline $\begin{array}{l}\text { Phospho-p38 MAPK (Thr180/Tyr182) } \\
\text { (12F8) Antibody }\end{array}$ & Rabbit monoclonal & Western & $1: 1000$ & Cell Signaling Technology, \# 4631 \\
\hline $\begin{array}{l}\text { Monoclonal Anti- } \beta \text {-Actin } \\
\text { Antibody Clone AC-15 }\end{array}$ & Mouse monoclonal & Western & $1: 40000$ & Sigma-Aldrich \#A5441 \\
\hline
\end{tabular}

488 (1-2 h at room temperature), counterstained with Hoechst 33342 (as described above for the blastocysts), mounted in Vectashield (Vector Laboratories) and observed using the confocal microscope (Leica TCS SP5, Leica Microsystems). To visualize the plasma membrane, F-actin staining with Phalloidin-Tetramethylrhodamine B isothiocyanate (5 min incubation at room temperature; Santa Cruz Biotechnology) was performed in some samples. Negative control groups of EBs were incubated without the primary antibody or without both the primary and secondary antibody.

\section{Glucose uptake studies}

\section{Blastocysts}

The blastocysts were isolated as described above, washed in several drops of FHM medium containing $0.1 \%$ BSA, and then pooled, randomly divided into experimental and control groups, washed in KSOM culture medium containing $5 \mathrm{mM}$ glucose, and transferred to culture drops (1 embryo/1 $\mu \mathrm{L}$ KSOM, covered with mineral oil). The culture drops of experimental groups were supplemented with adiponectin at a final concentration of $10 \mu \mathrm{g} / \mathrm{mL}$ (adiponectin water stock solution $(600 \mu \mathrm{g} / \mathrm{mL})$ was appropriately diluted with the KSOM culture medium). No supplement was added in the culture drops of the control (CTRL) group. The embryos were cultured in standard conditions $\left(5 \% \mathrm{CO}_{2}\right.$ and $\left.37^{\circ} \mathrm{C}\right)$ for $2 \mathrm{~h}$. Two isoforms of adiponectin were used in the experiments: full-length adiponectin (mouse Acrp30, recombinant protein, produced in HEK 293 cells, BioVendor; FLAD group) and the truncated isoform - globular adiponectin (mouse Acrp30, globular recombinant protein, produced in Escherichia coli, Abcam; GLAD group). Two experiments were carried out with each adiponectin isoform and the results were pooled.

Glucose uptake was measured as previously described (Fischer et al. 2010). In brief, after the 2-h culture with or without adiponectin, the embryos were washed three times in glucose-free FHM medium, and then transferred into $400-\mu \mathrm{L}$ pulse droplets, kept strictly at $37^{\circ} \mathrm{C}$ for $3 \mathrm{~min}$. The glucose-free pulse medium contained $0.3 \mathrm{mM} 3-\mathrm{O}-\mathrm{methyl-D-}$ [1-3H]glucose (3-OMG; $37 \mathrm{GBq} / \mathrm{L} ;$ Amersham) and $25 \mathrm{mM}$ 2,3,4,6-Tetra-O-methyl-D-glucose (Santa Cruz Biotechnology). The uptake was stopped after 3 min by transferring the embryos through four wash steps with ice-cold glucose-free FHM medium. Radioactivity of embryos was determined in a liquid scintillation counter (LSC) Wallac 1409 (PerkinElmer). We put five blastocysts to each sample and calculated the 3-OMG uptake in picomoles per minute per blastocyst.

\section{P19 cells}

Mouse embryonic carcinoma P19 cells were cultured as described above. Embryoid bodies were then randomly divided into several groups to measure glucose uptake. The two isoforms of adiponectin were used in the experiments and the final concentration of adiponectin in the culture medium was $10 \mu \mathrm{g} / \mathrm{mL}$. Groups containing 15-25 EBs were cultured in 96-well sterile cell culture plates in a volume of $180 \mu \mathrm{L}$ for $1 \mathrm{~h}$ under standard conditions $\left(5 \% \mathrm{CO}_{2}\right.$ and $\left.37^{\circ} \mathrm{C}\right)$ in the presence or absence (controls) of adiponectin.

In the first experiment, three groups were used: the CTRL group was cultured in the differentiation medium, the FLAD group was cultured in the differentiation medium supplemented with full-length adiponectin, and the GLAD group was cultured in the differentiation medium supplemented with globular adiponectin. To examine the effect of compound $\mathrm{C}$ on the full-length adiponectin-stimulated glucose uptake, a second experiment was performed. Three groups were used: the Control (DMSO) group was cultured in the differentiation medium supplemented with $0.1 \%$ DMSO (as compound C was dissolved in DMSO), the FLAD group was cultured in the differentiation medium containing $0.1 \%$ DMSO supplemented with full-length adiponectin, and the FLAD+CC group was cultured in the differentiation medium containing $0.1 \%$ DMSO supplemented with full-length adiponectin and 10 $\mu \mathrm{M}$ compound $\mathrm{C}$ (these cells were preincubated in medium with $10 \mu \mathrm{M}$ compound $\mathrm{C}$ for $30 \mathrm{~min}$ before the stimulation with full-length adiponectin; compound $\mathrm{C}$ was purchased from Sigma-Aldrich).

After $1 \mathrm{~h}$ culture with or without adiponectin, the EBs were washed three times in $400 \mu \mathrm{L}$ of glucose-free DMEM and transferred into $400 \mu \mathrm{L}$ pulse droplets, kept at $37^{\circ} \mathrm{C}$ for $3 \mathrm{~min}$. The glucose-free pulse medium contained $0.3 \mathrm{mM}$ 3-O-methyl-D-[1-3H] glucose ( ${ }^{3} \mathrm{H}$-OMG) (37 GBq/liter; Amersham Biosciences, Freiburg, Germany) and $25 \mathrm{mM}$ 3-OMG (Sigma-Aldrich). The uptake was stopped after $3 \mathrm{~min}$ 
by transferring the EBs through four wash steps with $400 \mu \mathrm{L}$ ice-cold glucose-free DMEM. The diameter of the EBs was recorded using a calibrated ocular micrometer. Radioactivity of individual EBs was determined in the LSC Walac 1409. The uptake of 3-OMG was expressed in $\mathrm{nmol} / \mathrm{vol}\left(\mathrm{cm}^{3}\right) \times 3 \mathrm{~min}$. The volume of the spherical EBs was calculated as $1 / 6 \mu \mathrm{d}^{3}$ and used to standardise the differences in size between EBs.

\section{Analysis of AMP and p38 MAP kinases in adiponectin- stimulated ECC P19 embryoid bodies}

The EBs were stimulated with full-length adiponectin for 5, 10, 15, 60 and 120 min. Specific AMPK inhibitor, Compound C (CC) was added before stimulation with adiponectin to check the AMPK dependency of downstream targets. For Western blot analysis, $25 \mu \mathrm{g}$ total protein lysates were subjected to SDS-polyacrylamide electrophoresis and electrotransferred to nitrocellulose membranes. For detection of p-p38 MAPK and $\beta$-Actin, the membranes were blocked in Tris-buffered saline containing $0.1 \%$ Tween with $3 \%$ (wt/vol) non-fat dry milk at room temperature for at least $1 \mathrm{~h}$. For pACC, PAMPK and AMPK detection, the membranes were blocked in Tris-buffered saline containing $0.1 \%$ Tween with $3 \%$ (wt/vol) BSA for at least $1 \mathrm{~h}$. The primary antibody was incubated at $4{ }^{\circ} \mathrm{C}$ overnight. Primary antibodies against the following targets were used: alpha subunit of AMP-activated protein kinase (AMPK), AMPK phosphorylated at threonine 172 (pAMPK), AcetylCoA Carboxylase phosphorylated at serine 79 (pACC), p38 MAP kinase phosphorylated at threonine 180 and tyrosine182 (p-p38MAPK) and $\beta$-actin. The antibodies were purchased from Cell Signaling Technology and Sigma-Aldrich (for detailed information see Table 1). Secondary antibodies conjugated to HRP (anti-rabbit IgG - HRP, DAKO Cytomation, Germany, 1:6000 and anti-mouse IgG - HRP, Dianova, Germany, $1: 20,000)$ were used to detect specific protein bands. The protein amount was calculated as the ratio of band intensities (pACC, p-p38 MAPK, AMPK, pAMPK protein vs $\beta$-actin protein and $p A M P K$ protein vs AMPK protein respectively) in the same blot to correct for differences in protein loading.

\section{Statistical analysis}

Statistical analysis was performed using GraphPad Prism software (GraphPad Software, Inc.). Student's t-test was used (after checking for normal distribution) to compare the relative quantity of two adiponectin receptor transcripts (AdipoR1 and AdipoR2) and two glucose transporter transcripts (GLUT4 and GLUT8). Student's t-test was used to compare the glucose uptake between control and adiponectin-stimulated blastocysts; one-way ANOVA and Tukey's post hoc test were used to compare the glucose uptake between the three groups of embryoid bodies. Relative protein amounts were evaluated using SimaPlot v.12.0 (Systat Software GmbH, Erkrath, Germany). Levels of significance between groups were calculated using Student's t-test after checking for normal distribution. Multiple comparisons were made by factorial variance analysis (ANOVA) adjusted according to Bonferroni. All experiments were repeated at least three times. Differences of $P<0.05$ were considered significant.

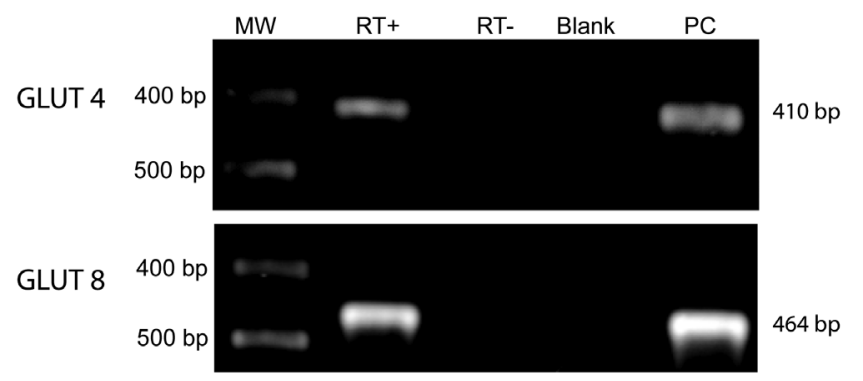

Figure 1 RT-PCR analysis of GLUT4 and GLUT8 transcripts in mouse blastocysts of CD-1 strain. Agarose gels with separated PCR products are shown. Lanes: MW, molecular weight markers; RT+, CDNA synthetised with reverse transcriptase; RT-, reverse transcriptase negative controls; Blank, reaction with water instead cDNA; PC, positive control tissue cDNA (heart for GLUT4, brain for GLUT8). The sizes of the MW and the predicted sizes of the PCR products in base pairs (bp) are indicated to the left and the right of the panels, respectively.

\section{Results}

\section{Expression of GLUT4 and GLUT8 transcripts in mouse blastocysts}

Controversial results have been published on the expression of GLUT4 in mouse blastocysts. We examined the expression of two hormone-responsive glucose transporters GLUT4 (S/C2a4) and GLUT8 (S/C2a8) in mouse blastocysts of CD-1 strain. We detected PCR products corresponding to both examined glucose transporters GLUT4 (410 bp) and GLUT8 (464 bp) in mouse blastocysts of CD-1 strain. No PCR products were detected in the reactions where reverse transcriptase (RT-) or cDNA (Blank) were omitted (Fig. 1). Sequencing the PCR products confirmed the GLUT4 and GLUT8 sequence: $100 \%$ sequence identity for GLUT4 and 99.8\% sequence identity for GLUT8 was found between the PCR products and corresponding GenBank reference sequences (NM_009204 and NM_019488 respectively).

\section{Expression of GLUT4 and GLUT8 proteins in mouse blastocysts and the effect of adiponectin on their intracellular localization}

Our immunohistochemical study showed the presence of GLUT4 and GLUT8 proteins in CD-1 mouse blastocysts. The fluorescence signal produced by GLUT4 was evenly distributed in TE and ICM cells, the signal for GLUT8 was slightly stronger in TE cells (Fig. 2A and C). No signal was detected in controls incubated without the primary antibody (Fig. 2E) or without the primary and the secondary antibody (data not shown). After stimulation with adiponectin $(10 \mu \mathrm{g} / \mathrm{mL}$ for $45 \mathrm{~min})$, GLUT8 relocated to the periphery of the cell (Fig. 2B vs A). On the other hand, we did not detect significant changes in GLUT4 localization after the adiponectin treatment (Fig. 2D vs C). 


\section{GLUT8}
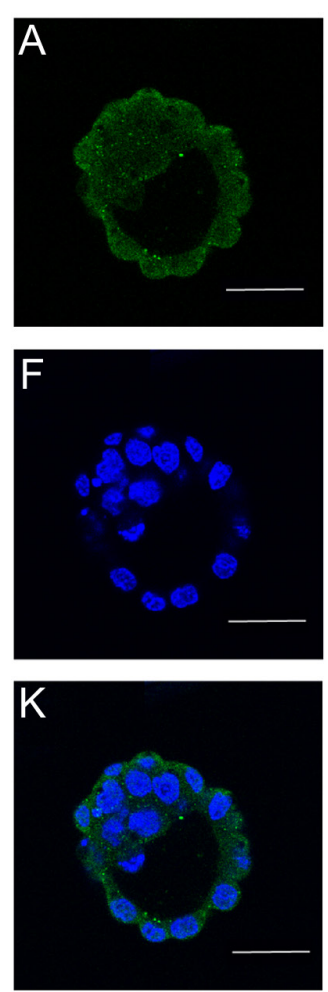
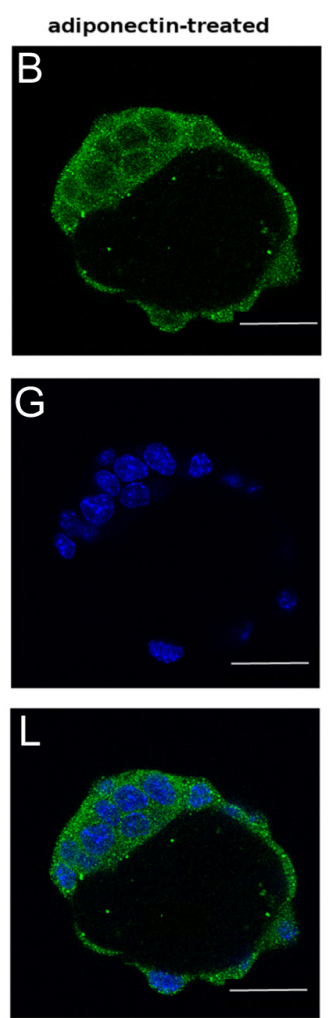

GLUT4
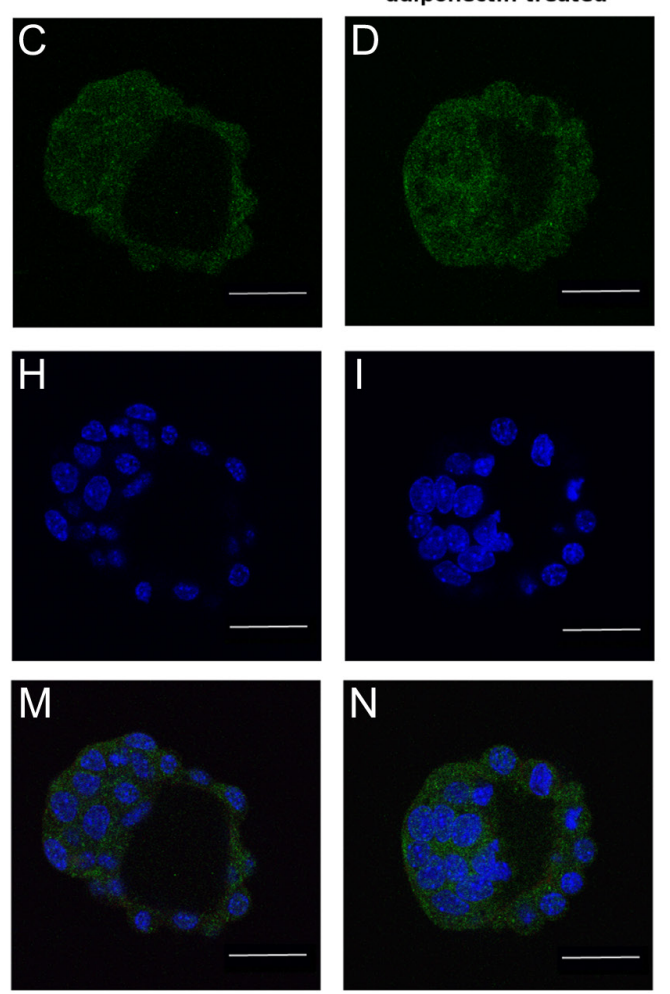

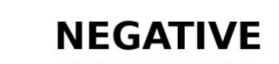
CONTROL
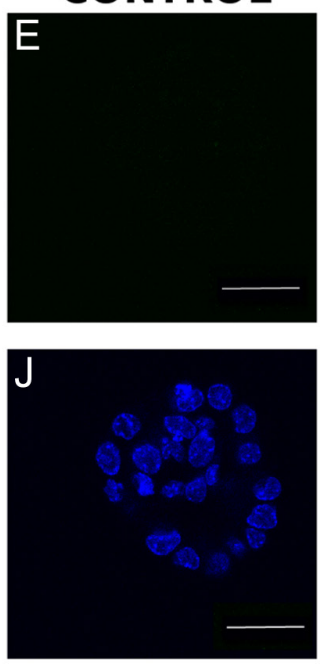

Figure 2 Immunohistochemical detection of GLUT4 and GLUT8 in mouse blastocysts of CD-1 strain. (A and B) Blastocysts incubated with the antibody against GLUT8 (green fluorescence signal); (C and D) blastocysts incubated with the antibody against GLUT4 (green fluorescence signal); (E) negative control with omitted primary antibody; ( $\mathrm{F}, \mathrm{G}, \mathrm{H}$, I and J) cell nuclei were counter-stained with Hoechst 33342 (blue fluorescence signal; identical samples as in images $A, B, C, D$ and $E) ;(K, L, M$ and $N)$ merged images $(K=A+F, L=B+G, M=C+H, N=D+I)$. Embryos presented in images $B,(G, L)$ and $D(I, N)$ were treated with adiponectin $(10 \mu g / m L$ for 45 min). Upon the adiponectin treatment, GLUT8 fluorescence signal was concentrated at the cell periphery (B vs. A). Only a slight increase in the GLUT4 signal intensity at the cell periphery was detected after the adiponectin treatment ( $\mathrm{D}$ vs $\mathrm{C}$ ). A representative staining of a blastocyst from each group is shown. Scale bars: $30 \mu \mathrm{m}$.

\section{Expression of AdipoR1 and AdipoR2 receptors in ECC P19 embryoid bodies}

Since no information on expression of AdipoR1 and AdipoR2 receptors in mouse embryonic carcinoma cells is currently available, we examined the expression of AdipoR1 and AdipoR2 receptors in embryoid bodies (EBs) formed from embryonic carcinoma P19 (ECC P19) cells. We detected PCR products corresponding to both adiponectin receptors AdipoR1 (132 bp) and AdipoR2 (258 bp) in the EBs formed from ECC P19 cells. No PCR products were detected in the reactions where reverse transcriptase or cDNA were omitted (Fig. 3A). Sequencing the PCR products confirmed the AdipoR1 and AdipoR2 sequence: 99,2\% sequence identity for AdipoR1 and 99.6\% sequence identity for AdipoR2 was found between the PCR products and corresponding GenBank reference sequences (NM_028320 and NM_197985 respectively).

In our immunohistochemical study we examined the presence of AdipoR1 and AdipoR2 proteins in the ECC P19 EBs. A strong fluorescence signal was detected in
EBs incubated with the antibody against the AdipoR1 and AdipoR2 respectively (Fig. 3B). A weak background signal was detected in controls incubated without primary (Fig. 3B) or without primary and secondary antibodies (data not shown).

\section{Expression of T-cadherin mRNA in mouse preimplantation embryos and ECC P19 embryoid bodies}

T-cadherin can bind several molecules including hexameric and high-molecular-weight forms of adiponectin (Hug et al. 2004). T-cadherin is expressed in different tissues (for review see Philippova et al. 2009); however, no data on its expression in early embryonic cells are available. We examined T-cadherin transcript expression in ovulated oocytes and preimplantation embryos at four developmental stages, using several independent cDNA samples for each stage (eight samples for blastocysts and five samples for lower embryo stages and oocytes were used). In ovulated oocytes, T-cadherin mRNA was consistently detected 


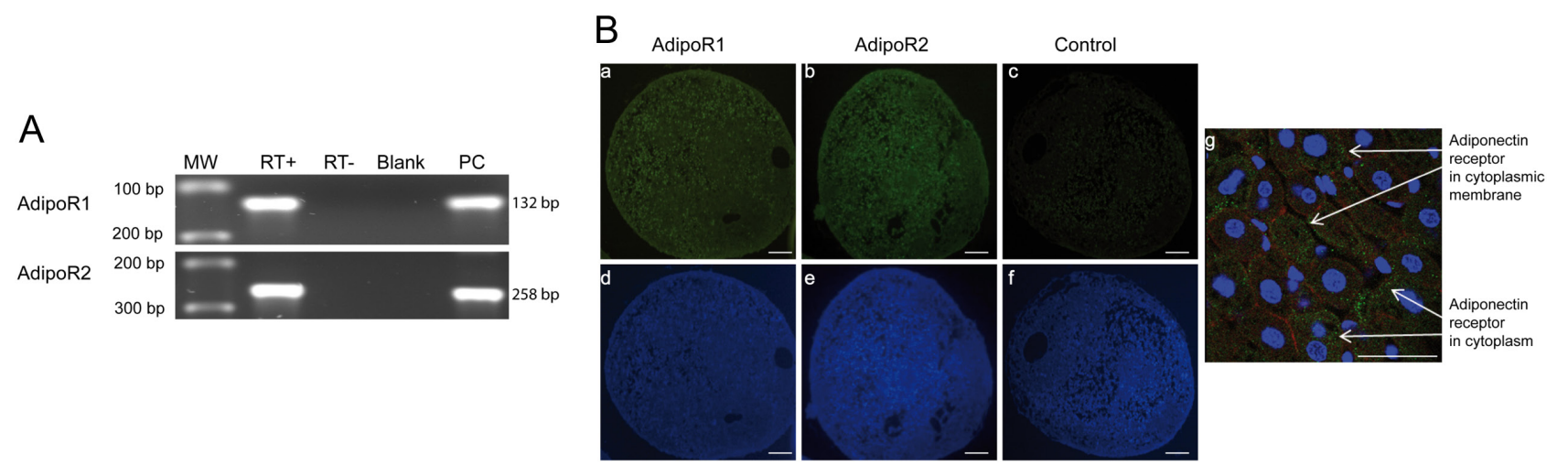

Figure 3 AdipoR1 and AdipoR2 expression in EBs formed from ECC P19 cells. (A) RT-PCR analysis of AdipoR1 and AdipoR2 receptor transcripts in ECC P19 EBs. Agarose gels with separated PCR products are shown. Lanes: MW, molecular weight markers; RT+, cDNA synthetised with reverse transcriptase; RT-, reverse transcriptase negative controls; Blank, reaction with water instead cDNA; PC, positive control tissue cDNA (brain). The sizes of the MW and the predicted sizes of the PCR products in base pairs (bp) are indicated to the right and the left of the panels, respectively. (B) Immmunohistochemical detection of AdipoR1 and AdipoR2 receptors in ECC P19 EBs (representative images are shown); (a and b) EBs incubated with the antibody against AdipoR1 and AdipoR2, respectively; (c) negative control with omitted primary antibody; (d, e and f) cell nuclei stained with Hoechst 33342 (identical samples as in images a, b and c). (g) Adiponectin receptor cellular localization; a merged image of F-actin staining (plasma membrane visualization, red), Hoechst 33342 staining (cell nuclei, blue) and the antibody against adiponectin receptor visualized with Alexa Fluor 488-coupled secondary antibody (green signal). Scale bars: $30 \mu \mathrm{m}$.

(i.e., in $100 \%$ samples). In preimplantation embryos, T-cadherin transcript was detected inconsistently: it was present in $40 \%$ of four-cell embryo samples, in $20 \%$ of 8- to 16 -cell embryo samples and in $37.5 \%$ of blastocyst samples; T-cadherin mRNA was not detected in any morula sample (Supplementary Fig. 1). In ECC P19 EBs we detected mRNA for T-cadherin in all four examined cDNA samples (Supplementary Fig. 2).

\section{Relative quantity of adiponectin receptor and glucose transporter transcripts in mouse blastocysts and ECC P19 embryoid bodies}

We compared the relative quantity of consistently expressed AdipoR1 and AdipoR2 transcripts, and GLUT4 and GLUT8 transcripts in both mouse blastocysts and ECC P19 EBs. Starting fluorescences (proportional to mRNA quantities) were calculated from AdipoR1, AdipoR2, GLUT4 and GLUT8 amplifications, and normalized with beta actin starting fluorescences. The normalized staring fluorescences are shown in Table 2. Our results showed that the amount of AdipoR1 transcript was about two times higher than the amount of AdipoR2 transcript in both cell types. The amount of GLUT8 transcript was much higher than the amount of GLUT 4 transcript in both cell types (about 15 times higher in blastocysts and about 10 times higher in embryoid bodies; Table 2).

\section{Effect of adiponectin on glucose uptake in mouse blastocysts and ECC P19 embryoid bodies}

We examined the effects of two adiponectin protein isoforms on glucose uptake in mouse blastocysts and ECC
P19 EBs. We found significantly higher uptake of 3-OMG in the blastocysts treated with full-length adiponectin (FLAD) compared to the control group (CTRL). On the other hand, we did not find any significant increase in glucose uptake after treatment with globular adiponectin (GLAD) compared to the control group (Fig. 4).

Similarly to the blastocysts, we found significantly higher uptake of 3-OMG in the ECC P19 EBs stimulated with full-length adiponectin compared to controls. No difference in glucose uptake between globular adiponectin-treated and control blastocysts was found (Fig. 5).

To study the involvement of AMP kinase, the effect of compound C (dorsomophin, a potent AMPK inhibitor) on the full-length adiponectin-stimulated glucose uptake was examined in the next experiment. The increased

Table 2 Relative quantity of AdipoR1 and AdipoR2 transcripts, and GLUT4 and GLUT8 transcripts in mouse blastocysts and ECC P19 EBs.

\begin{tabular}{lcc}
\hline Genes (ratios) & Blastocysts & ECC P19 Ebs \\
\hline AdipoR1 & $4.48 \pm 0.15$ & $2.13 \pm 0.10$ \\
AdipoR2 & $2.43 \pm 0.09^{* * *}$ & $1.04 \pm 0.06^{* * *}$ \\
AdipoR1/AdipoR2 ratio & $1.85 \pm 0.09$ & $2.05 \pm 0.08$ \\
GLUT4 & $7.77 \pm 0.49$ & $2.38 \pm 0.09$ \\
GLUT8 & $114.9 \pm 6.23^{* * *}$ & $24.29 \pm 2.45^{* * *}$ \\
GLUT8/GLUT4 ratio & $14.93 \pm 0.82$ & $10.24 \pm 0.78$ \\
\hline
\end{tabular}

Normalized starting fluorescences were multiplied by a factor of $1 \times 10^{2}$ (AdipoR1 and AdipoR2 fluorescences) or by a factor of $1 \times 10^{4}$ (GLUT4 and GLUT8 fluorescences) to obtain numbers in a more presentable format. Values are arithmetical means \pm S.E.M. $(n=6)$. Statistical significance of differences between AdipoR1 and AdipoR2 values, and between GLUT4 and GLUT8 values was assessed with unpaired Student's $t$-test: ${ }^{* * *} P<0.001$. 


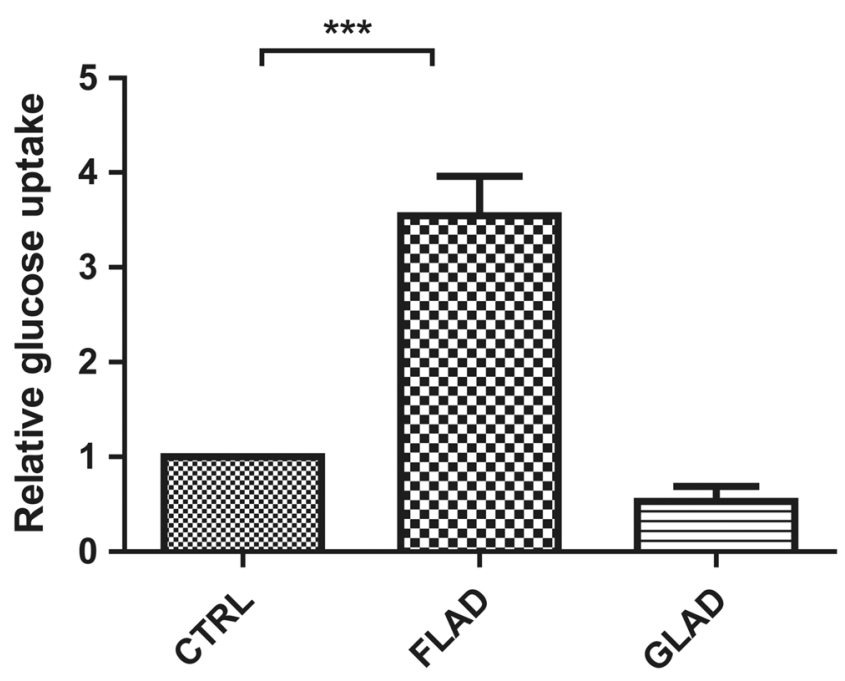

Figure 4 Uptake of glucose (3-OMG) in mice blastocysts. In the first set of experiments, the blastocysts were incubated in the presence or absence of full-length adiponectin for 2 h; CTRL, control blastocysts, $n=50$; FLAD, full-length adiponectin-treated blastocysts $n=70$ ( 5 blastocysts per sample were used for radioactivity measurement; data from two experiments were pooled). In the second set of experiments, the blastocysts were incubated in the presence or absence of globular adiponectin for $2 \mathrm{~h}$; CTRL, control blastocysts, $n=60$; GLAD, globular adiponectin-treated blastocysts, $n=70$ ( 5 blastocysts per sample were used for radioactivity measurement; data from two experiments were pooled). Statistical differences between the control and adiponectintreated groups were assessed with unpaired Student's $t$-test:

${ }^{* * *} P<0.001$. Means of the glucose uptake in control groups were set 1 and values of glucose uptake in adiponectin-treated groups are expressed relative to them. Values of relative glucose uptake in adiponectin-treated groups are arithmetical means + S.E.M.

glucose uptake in adiponectin-stimulated EBs was only slightly reduced through compound C treatment (Fig. 6).

\section{Activation of the adiponectin signaling pathway in ECC P19 embryoid bodies}

To analyse the involvement of AMP and p38 MAP kinases in adiponectin signaling the ECC P19 embryoid body model was used. Adiponectin treatment stimulated AMPK phosphorylation. This effect was detectable after 10-min treatment and was most evident after the 2-h treatment (Fig. 7). The adiponectin-induced phosphorylation of AMPK was blocked by AMPK inhibitor Compound C (Fig. 8). In correlation with AMPK activation, phosphorylation of ACC was tendentially increased (1.2 fold with $P=0.06)$, and this increase was reduced by Compound $C$ (Figs 7 and 8 ).

Adiponectin stimulated p38 MAPK phosphorylation after 5 and 10 min of treatment. After 60-min treatment the amount of phosphorylated p38 MAPK decreased to the unstimulated level (Fig. 7). Compound $\mathrm{C}$ did not influence the adiponectin-induced phosphorylation of p38 MAPK, indicating that AMPK did not mediate this effect (Fig. 8).

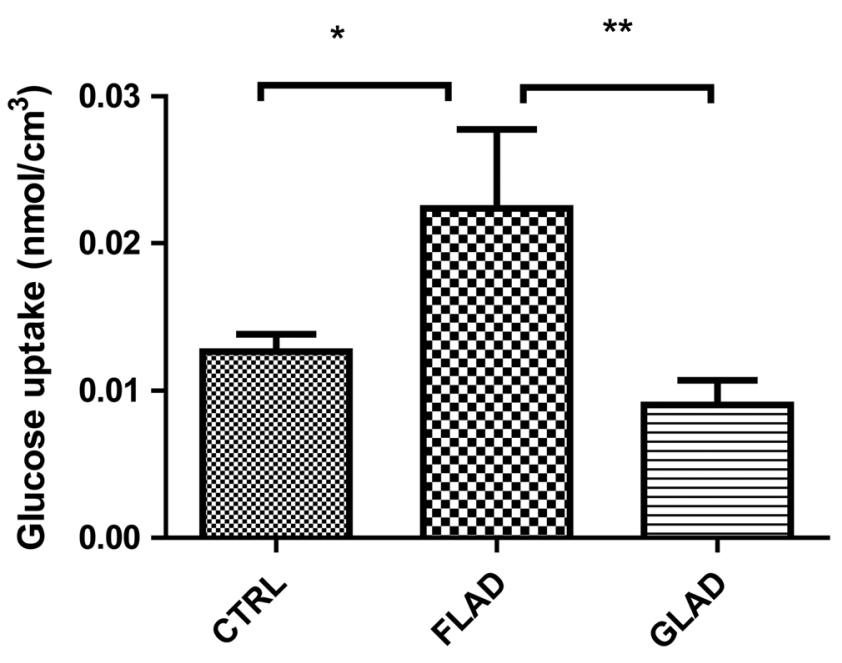

Figure 5 Uptake of glucose (3-OMG) in single ECC P19 EBs. The EBs were incubated in the presence or absence of full-length adiponectin or globular adiponectin for $1 \mathrm{~h}$. CTRL, control EBs $(n=35)$, FLAD, full-length adiponectin-treated EBs $(n=20)$; GLAD, globular adiponectin-treated EBs $(n=26)$. Values are arithmetical means + S.E.M. Statistical differences between the groups were assessed with ANOVA followed by Tukey's test, ${ }^{*} P<0.05,{ }^{* *} P<0.01$.

\section{Discussion}

Several studies have demonstrated that adiponectin is involved in the female fertility regulation and can influence oocyte maturation and preimplantation embryo development. Adiponectin receptors AdipoR1 and AdipoR2 have been detected in oocytes and

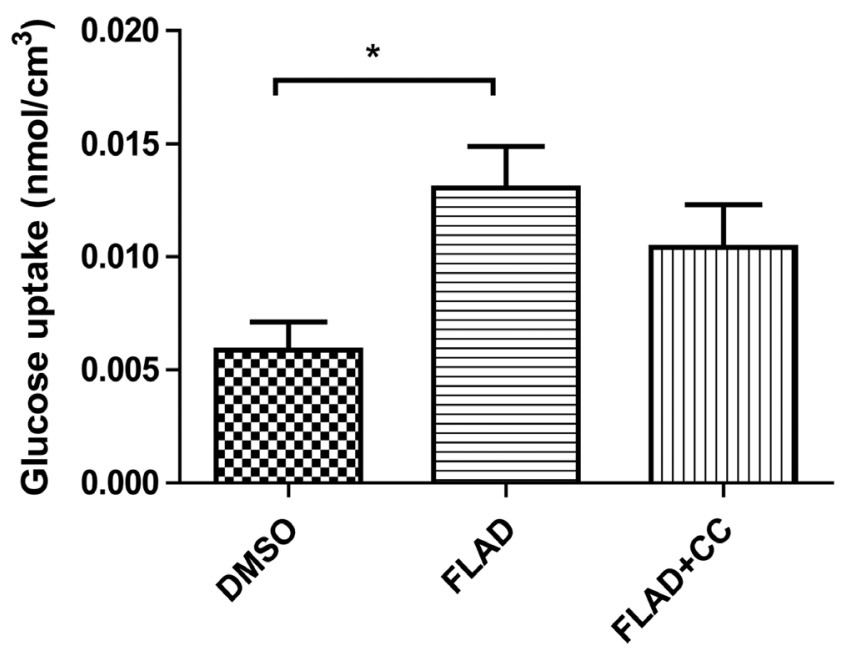

Figure 6 Effect of compound C on adiponectin-stimulated glucose uptake in ECC P19 EBs. The EBs were incubated in the presence or absence of full-length adiponectin or full-length adiponectin with $10 \mu \mathrm{M}$ compound C. DMSO, control EBs $(0.1 \%$ DMSO in the medium, $n=20)$; FLAD, full-length adiponectin-treated EBs $(n=20)$; $\mathrm{FLAD}+\mathrm{CC}$ full-length adiponectin and $10 \mu \mathrm{M}$ compound C-treated EBs $(n=19)$. Values are arithmetical means +S.E.M. Statistical differences between the groups were assessed with ANOVA followed by Tukey's test, $* P<0.05$. 

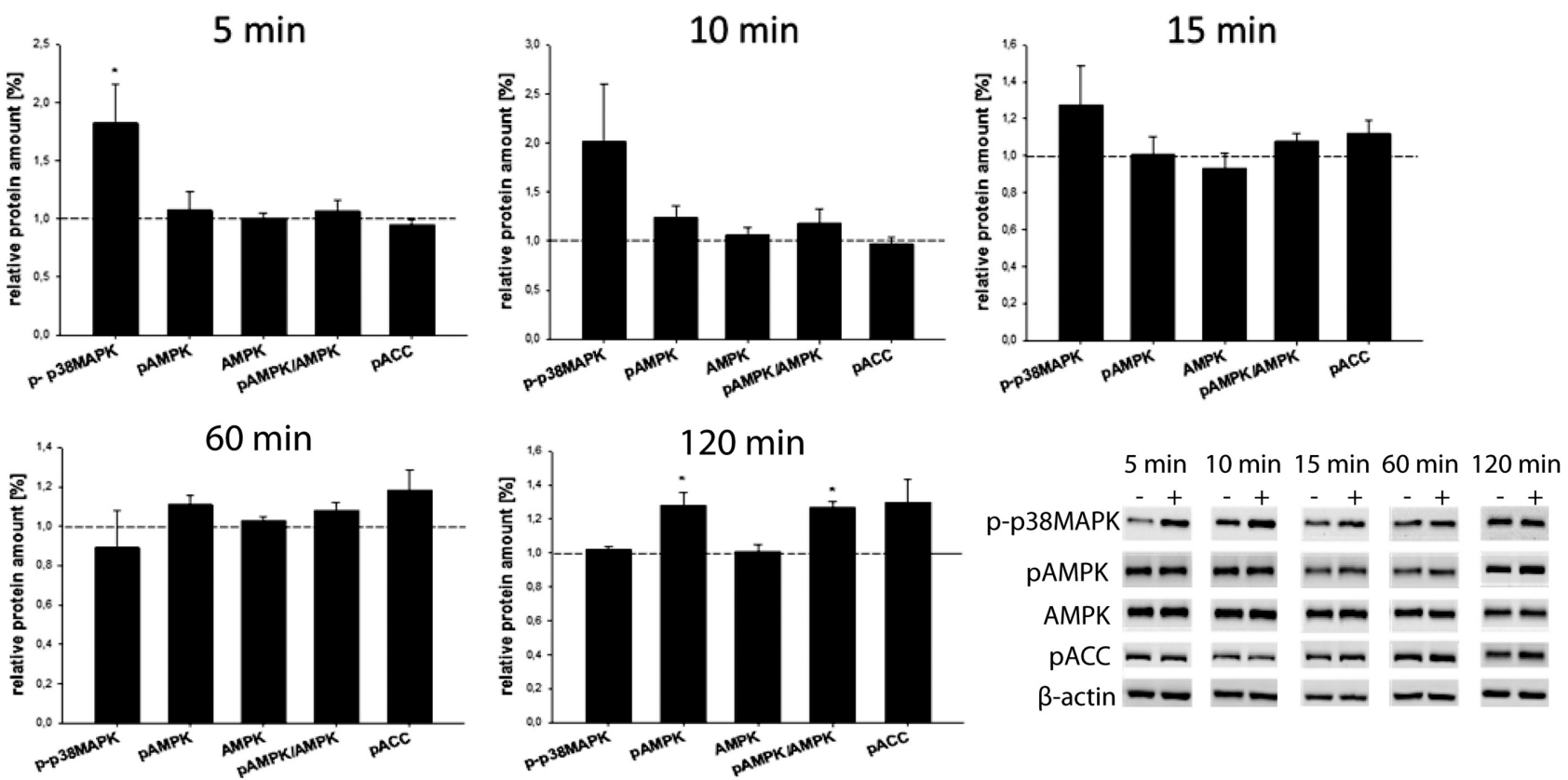

Figure 7 Relative protein amounts of phospho-p38 MAPK (p-p38MAPK), phospho-AMPK (pAMPK), AMPK and phospho-ACC (pACC) in adiponectin-stimulated P19 ECC EBs. Relative protein amounts after 5, 10, 15, 60 and 120 min of adiponectin treatment. Protein amounts are given relative to untreated controls which were set 1 and are indicated with the dashed line. Values are arithmetical means + S.E.M. $(n \geq 3)$. Statistical differences between the control and adiponectin-treated groups were assessed with unpaired Student's $t$-test: ${ }^{*} P<0.05$. Representative immunoblots are shown at the bottom right.

preimplantation embryos of several mammalian species (for review see Čikoš 2012, Palin et al. 2012, Dobrzyn et al. 2018, Barbe et al. 2019). The results presented in this work show that T-cadherin, the third putative adiponectin receptor, is expressed in mouse oocytes. Our results suggest that T-cadherin maternal transcript is gradually degraded after fertilization, and the expression is resumed at the blastocyst stage. T-cadherin is a glycosylphosphatidylinositol-anchored extracellular protein that may act as a coreceptor in adiponectin binding and signaling (Hug et al. 2004); however, the exact molecular mechanisms of adiponectin action in early embryonic cells are not known. There are data indicating that adiponectin (but not insulin) can stimulate glucose transport in rabbit blastocysts (Navarrete Santos et al. 2004a, Fischer et al. 2010). On the other hand, the stimulation of glucose uptake by insulin has been documented in mouse blastocysts (Pantaleon \& Kaye 1996, Carayannopoulos et al. 2000, Pinto et al. 2002). Our results show that, in addition to insulin, adiponectin is another hormone capable of stimulating glucose uptake in mouse blastocysts. Moreover, our comparison of two adiponectin isoforms shows that full-length adiponectin, but not globular adiponectin, can stimulate glucose uptake in mouse blastocysts. This is in contrast with data obtained from muscle cells, where globular
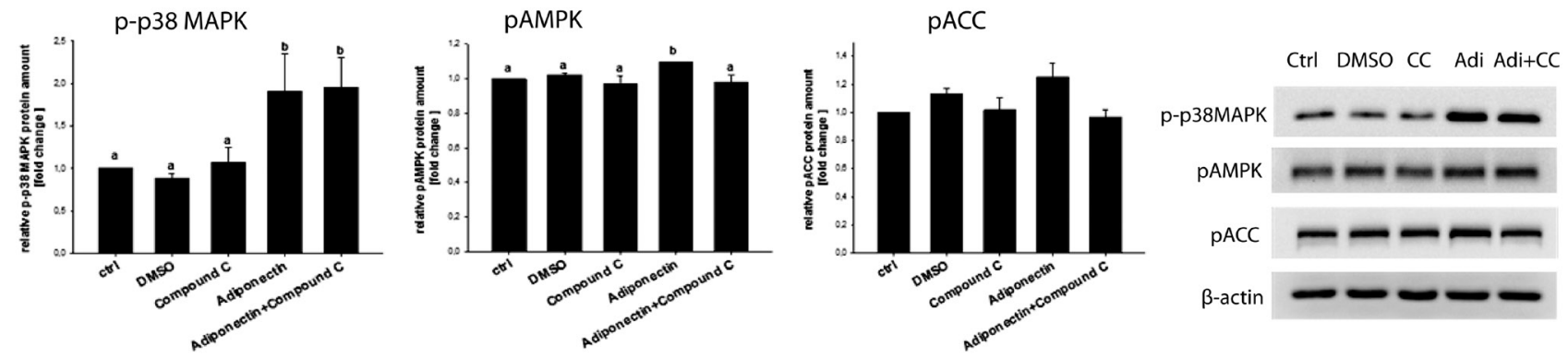

Figure 8 Effect of Compound C (CC) on adiponectin-stimulated protein amounts. Protein amounts after 10 min of adiponectin treatment are given relative to untreated controls (ctrl). Values are arithmetical means +S.E.M. $(n \geq 3)$. Statistical differences between the groups were assessed with factorial variance analysis (ANOVA) adjusted according to Bonferroni. Statistical significances are indicated with different letters $(P<0.05)$. Ctrl, EBs without treatment; DMSO (dimethyl sulfoxide), solvent control for Compound C. Representative immunoblots are shown at the bottom right. 
adiponectin was shown to stimulate glucose uptake. In other experiments using muscle cells, the globular but not the full-length isoform was effective (Ceddia et al. 2005, Fang et al. 2005, Palanivel et al. 2007, Vu et al. 2013).

In rabbit blastocysts, GLUT4 has been identified as the glucose transporter responsible for adiponectinstimulated glucose transport (GLUT8 was not examined for this function, Fischer et al. 2010). In mouse blastocysts, the expression of GLUT4 was disputed (Purcell \& Moley 2009), and GLUT8 was identified as the glucose transporter responsible for insulin-stimulated glucose transport (Carayannopoulos et al. 2000, Pinto et al. 2002). These data indicate that two insulin and/ or adiponectin-sensitive facilitative glucose transporters are expressed and function in preimplantation embryos. To answer the question whether both hormone-sensitive transporters are present in mouse blastocysts, we examined GLUT4 and GLUT8 expression and detected both transporters (at mRNA as well as protein level) in mouse CD-1 blastocysts. Comparing relative quantity of transcripts, we found that the amount of GLUT8 transcript was about 15 times higher than the amount of GLUT 4 transcript. Moreover, our results showed that GLUT8 protein translocated to the cell membrane in blastocyst cells stimulated with full-length adiponectin, indicating that GLUT8 is involved in the adiponectinstimulated glucose uptake in mouse blastocysts. On the other hand, we did not detect significant changes in GLUT4 protein localization after the adiponectin treatment, which could be caused by the lower amount of GLUT 4 than GLUT8 in mouse blastocyst cells.

Mouse blastocysts provide very limited amounts of biological material for biochemical analyses, so we used embryoid bodies (EBs) derived from mouse embryo carcinoma cell line P19 (ECC P19) as a model for studying adiponectin signaling in detail. To validate this model, we first examined the expression of adiponectin receptors in these cells. Our results show that adiponectin receptors are expressed in ECC P19 EBs and that the relative quantity of AdipoR1 and AdipoR2 transcripts is similar to that found in blastocysts. Several previous studies have demonstrated the expression of glucose transporters in ECC P19 EBs (Tonack et al. 2007, Knelangen et al. 2012), and the relative quantification of GLUT4 and GLUT8 mRNA showed a similar ratio of these transcripts in ECC P19 $\mathrm{EBs}$ and in mouse blastocysts. These results indicate that ECC P19 embryoid bodies represent a suitable model for the study of adiponectin signaling and glucose transport regulation in early embryonic cells.

Previous experimental data indicate that adiponectin regulates glucose and lipid metabolism via AMPK in rabbit blastocysts (Fischer et al. 2010, Schindler et al. 2017). We analysed the potential involvement of AMPK in the adiponectin-stimulated glucose uptake in mouse ECC P19 EBs. Administration of a potent
AMPK inhibitor, Compound C, only slightly reduced the adiponectin-stimulated glucose uptake which suggests that other signaling molecules participate in the regulation of glucose transport by adiponectin in these cells. Our next results supported this assumption. AMPK phosphorylation was moderately increased after $10 \mathrm{~min}$ of adiponectin treatment, and was most evident at the last checked time point in the 2-h treatment. A stronger response to adiponectin stimulation was observed in p38 MAPK, where the amount of phosphorylated protein doubled after 5 and 10 min of treatment. The AMPK inhibitor did not influence the adiponectinstimulated p38 MAPK phosphorylation, indicating independent actions of the two signaling pathways. These results indicate that the 38 MAPK protein is a potential target of adiponectin in mouse embryonic cells. Activation of p38 MAPK by adiponectin has been demonstrated in several cell types. Yamauchi et al. (2003) showed that besides AMPK, p38 MAPK activation mediated adiponectin-stimulated glucose uptake and fatty acid oxidation in C2C12 myocytes. Although some reports suggest that p38 MAPK activation is downstream to AMPK activation (Yoon et al. 2006), other studies have demonstrated AMPK-independent activation of p38 MAPK by adiponectin (Charlton et al. 2010, Xin et al. 2011). The involvement of p38 MAPK in the regulation of glucose transport has been shown in rat cardiomyocytes in primary culture, hibernating swine myocardium and human gastric cancer cells (McFalls et al. 2004, Montessuit et al. 2004, Liu et al. 2015). Studying early embryos, Sozen et al. (2015) demonstrated reduced glucose uptake and decreased GLUT4 expression in mouse preimplantation embryos treated with the p38 MAPK inhibitor SB203580. Rabbit blastocysts developing in diabetic conditions showed increased adiponectin signaling (Schindler et al. 2013) accompanied by increased p-p38 MAPK levels (Schindler et al. 2017).

The stimulation of glucose transport by adiponectin can be important in the case of reduced levels of circulating insulin. Elevation of adiponectin concentration has been well documented in patients with type 1 diabetes mellitus (Imagawa et al. 2002, Lindström et al. 2006, Majewska et al. 2016), although a controversy exists regarding the molecular mechanisms involved (Fasshauer et al. 2002, Blümer et al. 2008). Increased expression of AdipoR1 and AdipoR2 mRNAs has been found in the muscle tissue of streptozotocin-induced diabetic mice, and insulin administration restored the expression level (Tsuchida et al. 2004, Inukai et al. 2005). Negative correlation between adiponectin receptor expression and insulin has been confirmed in several studies. Insulin downregulated AdipoR1 and AdipoR2 transcripts in rat skeletal muscle (L6) cells, but not in mouse 3T3L1 adipocytes (Sattar \& Sattar 2012). On the other hand, the inhibitory effect of insulin on AdipoR2 mRNA expression was shown in porcine adipocytes (Liu et al. 
2008), and a similar effect of insulin on adiponectin receptor expression was demonstrated in mouse and human hepatocytes (Tsuchida et al. 2004, Shimizu et al. 2007) as well. These data indicate that a decrease in insulin can stimulate adiponectin action by elevating the adiponectin concentration in the circulation and by increasing adiponectin receptor expression in some tissues. Increased expression of AdipoR1 transcript found in rabbit blastocysts isolated from diabetic females suggests a compensatory role of adiponectin for lack of insulin in early embryos (Schindler et al. 2013).

In summary our results demonstrate that besides insulin, adiponectin can be another hormone capable of stimulating glucose uptake in mouse blastocysts. We show that both hormone-sensitive facilitative glucose transporters (GLUT4 and GLUT8) are expressed in mouse blastocysts and especially GLUT8 is involved in the adiponectin-stimulated glucose uptake. Using a mouse embryonic carcinoma cell model, we show that besides AMPK, p38 MAPK participates in adiponectin signaling in early embryonic cells. Our results suggest that adiponectin can help maintain the glucose supply for early embryos under hypoinsulinaemic conditions, for example, in mothers suffering from type 1 diabetes mellitus.

\section{Supplementary materials}

This is linked to the online version of the paper at https://doi.org/10.1530/REP-19-0251.

\section{Declaration of interest}

The authors declare that there is no conflict of interest that could be perceived as prejudicing the impartiality of the research reported.

\section{Funding}

This study was supported by an exchange program between Germany and Slovakia (DAAD-SAV, Hormonal dysregulations in a diabetic pregnancy), EU COST Action FA1201 Epiconcept, the Slovak Academy of Sciences project VEGA 2/0092/19, the Slovak Research and Development Agency project APVV-180389, by project No. ITMS 26220120066 of the Research and Development Operational Programme funded by the ERDF and by the German Research Foundation GRK 2155 PromoAge.

\section{Author contribution statement}

J Bu and J Ba designed and performed experiments, analysed and interpreted data. M S, J S J, A Š, M K and V K performed experiments and analysed results. D F was involved in designing experiments, analysed and interpreted data, critically revised the article. B F and J K interpreted data and critically revised the article. A N S contributed to the conception of the work, designed and performed experiments and analysed results. $\breve{S} \breve{C}$ contributed to the conception of the work, designed experiments, analysed and interpreted data and wrote the article.

\section{References}

Aghayan M, Rao LV, Smith R M, Jarett L, Charron MJ, Thorens B \& Heyner S 1992 Developmental expression and cellular localization of glucose transporter molecules during mouse preimplantation development. Development 115 305-312.

Augustin R, Pocar P, Navarrete-Santos A, Wrenzycki C, Gandolfi F, Niemann H \& Fischer B 2001 Glucose transporter expression is developmentally regulated in in vitro derived bovine preimplantation embryos. Molecular Reproduction and Development 60 370-376. (https://doi.org/10.1002/mrd.1099)

Barbe A, Bongrani A, Mellouk N, Estienne A, Kurowska P, Grandhaye J, Elfassy Y, Levy R, Rak A, Froment P \& Dupont J 2019 Mechanisms of adiponectin action in fertility: an overview from gametogenesis to gestation in humans and animal models in normal and pathological conditions. International Journal of Molecular Science 20 E1526. (https:// doi.org/10.3390/ijms20071526)

Blümer RME, van Roomenb CP, Meijerb AJ, Houben-Weertsb JHPM, Sauerweina HP \& Dubbelhuisb PF 2008 Regulation of adiponectin secretion by insulin and amino acids in 3T3-L1 adipocytes. Metabolism Clinical and Experimental 57 1655-1662. (https://doi.org/10.1016/j. metabol.2008.07.020)

Carayannopoulos MO, Chi MM, Cui Y, Pingsterhaus JM, McKnight RA, Mueckler M, Devaskar SU \& Moley KH 2000 GLUT8 is a glucose transporter responsible for insulin-stimulated glucose uptake in the blastocyst. PNAS 97 7313-7318. (https://doi.org/10.1073/ pnas.97.13.7313)

Ceddia RB, Somwar R, Maida A, Fang X, Bikopoulos G \& Sweeney G 2005 Globular adiponectin increases GLUT4 translocation and glucose uptake but reduces glycogen synthesis in rat skeletal muscle cells. Diabetologia 48 132-139. (https://doi.org/10.1007/s00125-004-1609-y)

Charlton HK, Webster J, Kruger S, Simpson F, Richards AA \& Whitehead JP 2010 ERp46 binds to AdipoR1, but not AdipoR2, andmodulates adiponectin signalling. Biochemical and Biophysical Research Communnications 392 234-239. (https://doi.org/10.1016/j. bbrc.2010.01.029)

Čikoš S 2012 Adiponectin and its receptors in preimplantation embryo development. In Adiponectin, Vitamins and Hormones, vol 90, pp 211-238. Ed G Litwack. Academic Press, Elsevier.

Čikoš Š \& Koppel J. 2009 Transformation of real-time PCR fluorescence data to target gene quantity. Analytical Biochemistry 384 1-10. (https:// doi.org/10.1016/j.ab.2008.08.031)

Dobrzyn K, Smolinska N, Kiezun M, Szeszko K, Rytelewska E, Kisielewska K, Gudelska M \& Kaminski T 2018 Adiponectin: a new regulator of female reproductive system. International Journal of Endocrinology 2018 ID7965071, 12 pages. (https://doi.org/10.1155/2018/7965071)

Fang X, Palanivel R, Zhou X, Liu Y, Xu A, Wang Y \& Sweeney G 2005 Hyperglycemia- and hyperinsulinemia-induced alteration of adiponectin receptor expression and adiponectin effects in L6 myoblasts. Journal of Molecular Endocrinology 35 465-476. (https://doi.org/10.1677/ jme.1.01877)

Fasshauer M, Klein J, Neumann S, Eszlinger M \& Paschke R 2002 Hormonal regulation of adiponectin gene expression in 3T3-L1 adipocytes. Biochemical and Biophysical Research Communications 290 1084-1089. (https://doi.org/10.1006/bbrc.2001.6307)

Fischer S, Navarrete Santos A, Thieme R, Ramin N \& Fischer B 2010 Adiponectin stimulates glucose uptake in rabbit blastocysts. Biology of Reproduction 83 859-865. (https://doi.org/10.1095/ biolreprod.110.084665)

Hogan A, Heyner S, Charron MJ, Copeland NG, Gilbert DJ, Jenkins NA, Thorens B \& Schultz GA 1991 Glucose transporter gene expression in early mouse embryos. Development 113 363-372.

Hug C, Wang J, Ahmad NS, Bogan JS, Tsao TS \& Lodish HF 2004 T-cadherin is a receptor for hexameric and high-molecular-weight forms of Acrp30/ adiponectin. PNAS 101 10308-10313. (https://doi.org/10.1073/ pnas.0403382101) 
Imagawa A, Funahashi T, Nakamura T, Moriwaki M, Tanaka S, Nishizawa $\mathbf{H}_{\text {, }}$ Sayama K, Uno S, Iwahashi H, Yamagata K et al. 2002 Elevated serum soncentration of adipose-derived factor, adiponectin, in patients with type 1 diabetes. Diabetes Care 25 1665-1666. (https://doi.org/10.2337/ diacare.25.9.1665)

Inukai K, Nakashima Y, Watanabe M, Takata N, Sawa T, Kurihara S, Awata T \& Katayama S 2005 Regulation of adiponectin receptor gene expression in diabetic mice. American Journal of Physiology, Endocrinology and Metabolism 288 E876-E882. (https://doi. org/10.1152/ajpendo.00118.2004)

Knelangen JM, Kurz R, Schagdarsurengin U, Fischer B \& Navarrete Santos A 2012 Short-time glucose exposure of embryonic carcinoma cells impairs their function as terminally differentiated cardiomyocytes. Biochemical and Biophysical Research Communications 420 230-235. (https://doi.org/10.1016/j.bbrc.2012.02.105)

Korgun ET, Demir R, Hammer A, Dohr G, Desoye G, Skofitsch G \& Hahn T 2001 Glucose transporter expression in rat embryo and uterus during decidualization, implantation, andearly postimplantation. Biology of Reproduction 65 1364-1370. (https://doi.org/10.1095/ biolreprod65.5.1364)

Lawits JA \& Biggers JD 1993 Culture of preimplantation embryos. In Guide to Techniques in Mouse Development, Methods in Enzymology, pp 153-164. Eds Wassarman PM \& DePhamphilis ML. San Diego: Academic Press.

Lindström T, Frystyk J, Hedman CA, Flyvbjerg A \& Arnqvist HJ 2006 Elevated circulating adiponectin in type 1 diabetes is associated with long diabetes duration. Clinical Endocrinology 65 776-782.

Liu W \& Saint DA 2002 Validation of a quantitative method for real time PCR kinetics. Biochemical and Biophysical Research Communications 294 347-353. (https://doi.org/10.1016/S0006-291X(02)00478-3)

Liu BH, Wang YC, Wu SC, Mersmanna HJ, Cheng WTK \& Ding ST 2008 Insulin regulates the expression of adiponectin and adiponectin receptors in porcine adipocytes. Domestic Animal Endocrinology 34 352-359. (https://doi.org/10.1016/j.domaniend.2007.10.003)

Liu J, Wen D, Fang X, Wang X, Liu T \& Zhu J 2015 p38MAPK signaling enhances glycolysis through the up-regulation of the glucose transporter GLUT-4 in gastric cancer cells. Cellular Physiology and Biochemistry 36 155-165. (https://doi.org/10.1159/000374060)

Majewska KA, Majewski D, Skowronska B, Stankiewicz W \& Fichna P 2016 Serum leptin and adiponectin levels in children with type 1 diabetes mellitus - relation to body fat mass and disease course. Advances in Medical Sciences 61 117-122. (https://doi.org/10.1016/j. advms.2015.10.002)

McBurney MW, Jones-Villeneuve EM, Edwards MK \& Anderson PJ 1982 Control of muscle and neuronal differentiation in a cultured embryonal carcinoma cell line. Nature 299 165-167. (https://doi. org/10.1038/299165a0)

McFalls EO, Hou MX, Bache RJ, Best A, Marx D, Sikora J \& Ward HB 2004 Activation of p38 MAPK and increased glucose transport in chronic hibernating swine myocardium. American Journal of Physiology: Heart and Circulatory Physiology 287 H1328-H1334. (https://doi.org/10.1152/ ajpcell.00162.2004)

Montessuit C, Rosenblatt-Velin N, Papageorgiou I, Campos L, Pellieux C, Palma T \& Lerch R 2004 Regulation of glucose transporter expression in cardiac myocytes: p38 MAPK is a strong inducer of GLUT4. Cardiovascular Research 64 94-104. (https://doi.org/10.1016/j. cardiores.2004.06.005)

Navarrete Santos A, Augustin R, Lazzari G, Galli C, Sreenan JM \& Fischer B 2000 The insulin-dependent glucose transporter isoform4 is expressed in bovine blastocysts. Biochemical and Biophysical Research Communications 271 753-760. (https://doi.org/10.1006/ bbrc.2000.2646)

Navarrete Santos A, Tonack S, Kirstein M, Pantaleon M, Kaye P \& Fischer B $2004 a$ Insulin acts via mitogen-activated protein kinase phosphorylation in rabbit blastocysts. Reproduction 128 517-526. (https://doi. org/10.1530/rep.1.00204)

Navarrete Santos A, Tonack S, Kirstein M, Kietz S \& Fischer B $2004 b$ Two insulin-responsive glucose transporter isoforms and the insulin receptor are developmentally expressed in rabbit preimplantation embryos. Reproduction 128 503-516. (https://doi.org/10.1530/rep.1.00203)

Palanivel R, Fang X, Park M, Eguchi M, Pallan S, De Girolamo S, Liu Y, Wang Y, Xu A \& Sweeney G 2007 Globular and full-length forms of adiponectin mediate specific changes in glucose and fatty acid uptake and metabolism in cardiomyocytes. Cardiovascular Research 75 148-157. (https://doi.org/10.1016/j.cardiores.2007.04.011)

Palin MF, Bordignon VV \& Murphy BD 2012 Adiponectin and the control of female reproductive functions. In Adiponectin, Vitamins and Hormones, vol 90, pp 239-287. Ed G Litwack. Academic Press, Elsevier.

Pantaleon M \& Kaye PL 1996 IGF-I and insulin regulate glucose transport in mouse blastocysts via IGF-I receptor. Molecular Reproduction and Development 44 71-76. (https://doi.org/10.1002/(SICI)10982795(199605)44:1<71::AID-MRD8>3.0.CO;2-Q)

Pantaleon M \& Kaye PL 1998 Glucose transporters in preimplantation development. Reviews of Reproduction 3 77-81. (https://doi. org/10.1530/ror.0.0030077)

Peirson SN, Butler JN \& Foster RG 2003 Experimental validation of novel and conventional approaches to quantitative real-time PCR data analysis. Nucleic Acids Research 31 e73. (https://doi.org/10.1093/nar/gng073)

Philippova M, Joshi MB, Kyriakakis E, Pfaff D, Erne P \& Resink TJ 2009 A guide and guard: the many faces of T-cadherin. Cellular Signalling $\mathbf{2 1}$ 1035-1044. (https://doi.org/10.1016/j.cellsig.2009.01.035)

Pinto AB, Carayannopoulos MO, Hoehn A, Dowd L \& Moley KH 2002 Glucose transporter 8 expression and translocation are critical for murine blastocyst survival. Biology of Reproduction 66 1729-1733. (https://doi. org/10.1095/biolreprod66.6.1729)

Purcell SH \& Moley KH 2009 Glucose transporters in gametes and preimplantation embryos. Trends Endocrinology and Metabolism 20 483-489. (https://doi.org/10.1016/j.tem.2009.06.006)

Ramakers C, Ruijter JM, Deprez RH \& Moorman AF 2003 Assumptionfree analysis of quantitative real-time polymerase chain reaction (PCR) data. Neuroscience Letters 339 62-66 (https://doi.org/10.1016/S03043940(02)01423-4)

Sattar AA \& Sattar R 2012 Insulin-regulated expression of adiponectin receptors in muscle and fat cells. Cell Biology International 36 1293-1297. (https://doi.org/10.1042/CBI20120294)

Schindler M, Fischer S, Thieme R, Fischer B \& Navarrete Santos A 2013 CAMP-responsive element binding protein: a vital link in embryonic hormonal adaptation. Endocrinology 154 2208-2221. (https://doi. org/10.1210/en.2012-2096)

Schindler M, Pendzialek M, Grybel KJ, Seeling T, Gürke J, Fischer B \& Navarrete Santos A 2017 Adiponectin stimulates lipid metabolism via AMPK in rabbit blastocysts. Human Reproduction 32 1382-1392. (https://doi.org/10.1093/humrep/dex087)

Schmidt T, Fischer S, Tsikolia N, Santos AN, Rohrbach S, Ramin N, Thieme R \& Fischer B. 2008 Expression of adipokines in preimplantation rabbit and mice embryos. Histochemistry and Cell Biology 129 817825. (https://doi.org/10.1007/s00418-008-0409-8)

Shimizu A, Takamura T, Matsuzawa N, Nakamura S, Nabemoto S, Takeshita Y, Misu H, Kurita S, Sakurai M, Yokoyama M et al. 2007 Regulation of adiponectin receptor expression in human liver and a hepatocyte cell line. Metabolism Clinical and Experimental 56 1478-1485. (https://doi.org/10.1016/j.metabol.2007.06.013)

Sozen B, Ozturk S, Yaba A \& Demir N 2015 The p38 MAPK signalling pathway is required for glucose metabolism, lineage specification and embryo survival during mouse preimplantation development. Mechanisms of Development 138 375-398. (https://doi.org/10.1016/j. mod.2015.05.002)

Tonack S, Fischer B \& Navarrete Santos A 2004 Expression of the insulinresponsive glucose transporter isoform 4 in blastocysts of C57/BL6mice. Anatomy and Embryology 208 225-230.

Tonack S, Rolletschek A, Wobus AM, Fischer B \& Santos AN 2006 Differential expression of glucose transporter isoforms during embryonic stem cell differentiation. Differentiation 74 499-509. (https://doi. org/10.1111/j.1432-0436.2006.00091.x)

Tonack S, Kind K, Thompson JG, Wobus AM, Fischer B \& Navarrete Santos A 2007 Dioxin affects glucose transport via the arylhydrocarbon receptor signal cascade in pluripotent embryonic carcinoma cells. Endocrinology 148 5902-5912. (https://doi.org/10.1210/en.2007-0254)

Tonack S, Ramin N, Garimella S, Rao R, Seshagiri PB, Fischer B \& Navarrete Santos A 2009 Expression of glucose transporter isoforms and the insulin receptor during hamster preimplantation embryo development. Annals of Anatomy 191 485-495. (https://doi.org/10.1016/j.aanat.2009.06.002)

Tsuchida A, Yamauchi T, Ito Y, Hada Y, Maki T, Takekawa S, Kamon J, Kobayashi M, Suzuki R, Hara K et al. 2004 Insulin/Foxo1 pathway 
regulates expression levels of adiponectin receptors and adiponectin sensitivity. Journal of Biological Chemistry 279 30817-30822. (https:// doi.org/10.1074/jbc.M402367200)

Vu V, Bui P, Eguchi M, Xu A \& Sweeney G 2013 Globular adiponectin induces LKB1/AMPK-dependent glucose uptake via actin cytoskeleton remodeling. Journal of Molecular Endocrinology 51 155-165. (https:// doi.org/10.1530/JME-13-0059)

Wobus AM, Kleppisch T, Maltsev V \& Hescheler J 1994 Cardiomyocytelike cells differentiated in vitro from embryonic carcinoma cells P19 are characterized by functional expression of adrenoceptors and $\mathrm{Ca} 2+$ channels. In Vitro Cellular and Developmental Biology: Animal 30A 425-434. (https://doi.org/10.1007/BF02631310)

Xin X, Zhou L, Reyes CM, Liu F \& Dong LQ 2011 APPL1 mediates adiponectin-stimulated p38 MAPK activation by scaffolding the TAK1-MKK3-p38 MAPK pathway. American Journal of Physiology: Endocrinology and Metabolism 300 E103-E110. (https://doi.org/10.1152/ ajpendo.00427.2010)

Yamauchi T, Kamon J, Ito Y, Tsuchida A, Yokomizo T, Kita S, Sugiyama T, Miyagishi M, Hara K, Tsunoda M et al. 2003 Cloning of adiponectin receptors that mediate antidiabetic metabolic effects. Nature $\mathbf{4 2 3}$ 762-769. (https://doi.org/10.1038/nature01705)

Yoon MJ, Lee GY, Chung JJ, Ahn JH, Hong SH \& Kim JB 2006 Adiponectin increases fatty acid oxidation in skeletal muscle cells by sequential activation of AMP-activated protein kinase, p38 mitogen-activated protein kinase, and peroxisome proliferator-activated receptor $\alpha$. Diabetes 55 2562-2570. (https://doi.org/10.2337/db05-1322)

Zhou S, Matsuyoshi N, Liang SB, Takeuchi T, Ohtsuki Y \& Miyachi Y 2002 Expression of T-cadherin in basal keratinocytes of skin. Journal of Investigative Dermatology 118 1080-1084. (https://doi.org/10.1046/ j.1523-1747.2002.01795.x)

Received 6 June 2019

First decision 29 July 2019

Revised manuscript received 4 November 2019

Accepted 19 December 2019 